\title{
EFFICACY OF ADSORBENTS FOR 2,4-D AND ATRAZINE REMOVAL FROM WATER ENVIRONMENT
}

\author{
J.B. ALAM \\ A.K. DIKSHIT* and \\ M.BANDYOPADHYAY
}

Received: $07 / 01 / 00$

Accepted: 18/07/00

\author{
Indian Institute of Technology \\ Department of Civil Engineering \\ Khargapur - 721302 India
}

* to whom all correspondence should be addressed e-mail: anil@civil.iitkgp.ernet.in

Fax: + $91-3222-55303$

\begin{abstract}
The efficacy of low cost adsorbing materials for removal of 2,4-D (2,4 dichloro phenoxy acetic acid) and atrazine (2-chloro-4-ethyamino-6-isopropylamino-1,3,5 triazine) herbicides from drinking water was evaluated. Five low cost adsorbents, viz. wood charcoal, rubber granules, bottom ash, macro fungi sajor caju and florida were tested. The above materials were selected from organic, inorganic and biological sources. For the selection of the suitable adsorbent for 2,4-D and atrazine uptake, the maximum adsorption capacity $\left(\mathrm{Q}_{\max }\right)$ was chosen as the main parameter. Using linearized forms of equilibrium models like Langmuir, Brunauer, Emmett and Teller (BET), Freundlich and Lopez-Gonzalez models (L-G models), the maximum adsorptive capacities were determined. Wood charcoal showed the best adsorptive capacity with $\mathrm{Q}_{\max }$ of $0.70 \mathrm{mg} \mathrm{g}^{-1}$ for 2,4-D and $0.80 \mathrm{mg} \mathrm{g}^{-1}$ for atrazine followed by $0.40 \mathrm{mg} \mathrm{g}^{-1}$ for 2,4-D and $0.47 \mathrm{mg} \mathrm{g}^{-1}$ for atrazine by rubber granules. Bottom ash, sajor caju and florida gave poor performance.
\end{abstract}

KEY WORDS: Maximum adsorption capacity, Langmuir, Freundlich, BET, L-G models, Herbicides

\section{INTRODUCTION}

Water is a basic need of life and is used in many ways to cater the needs of daily life. Indiscriminate use of pesticides in the modern agricultural practices leads to the contamination of soils, surface and ground waters. Figure 1 shows the typical pesticide use pattern in some areas of Bangladesh based on data collected during the survey work of National Minor Irrigation Development Project, Bangladesh during 1994 to 1995 (NMIDP, 1995). Numerous cases of pesticide residue have been reported in the literature (Moore and Ramamoorthy, 1984; Halder et al.,
1989). Their residual concentrations in the food products are alarming especially in the developing countries. Leafy vegetables, cereals, fruits, rice, meat, milk, fish intestine and edible portions and even human milk have been reported to be contaminated by various pesticides in a range of concentrations $0.1 \mathrm{mg} \mathrm{l}^{-1}-25.7 \mathrm{mg} \mathrm{l}^{-1}$ (Srivastava and Patel, 1990). Natural waters, viz. lakes, rivers, streams, and oceans have been reported contaminated with residue of various pesticides (Joshi et al., 1975; Thakkar and Muthal, 1980; Subbarao et al., 1986; Thakkar and Pande, 1986; Halder et al., 1989; Ramachandran et al., 1991; Rao, 1996; 


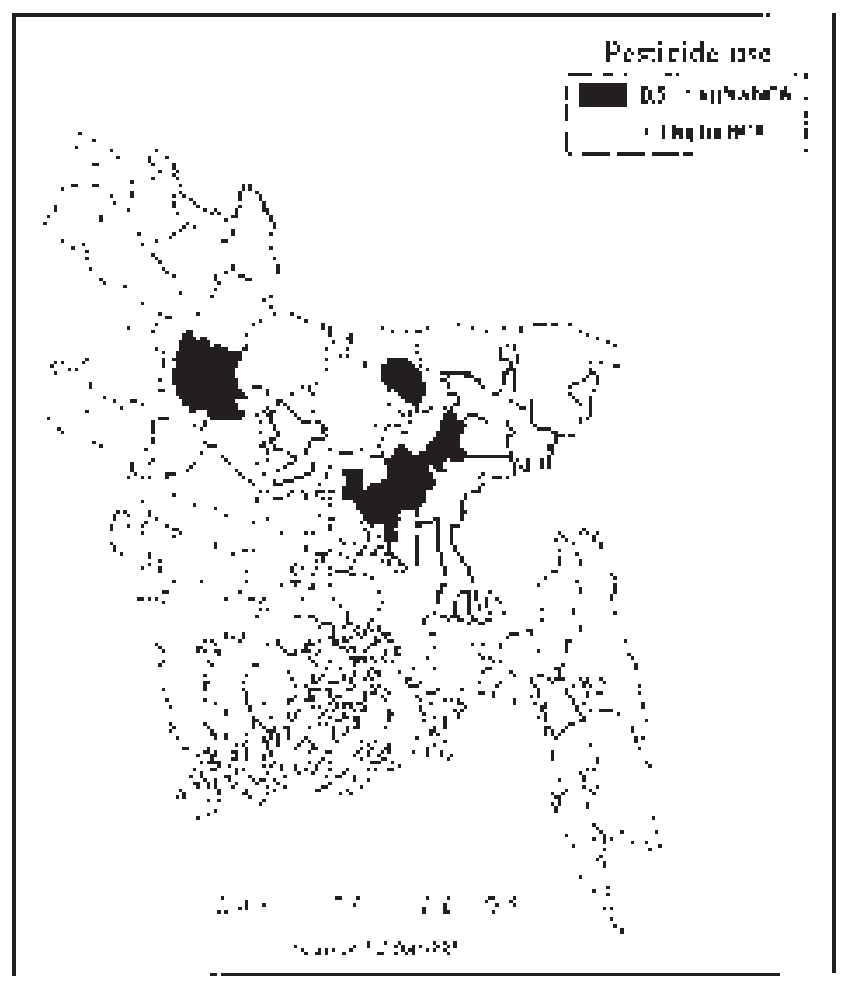

Figure 1. Pesticides use pattern in some areas of Bangladesh.

Hatfield et al., 1996; Mc Terron and Pereira, 1991 and Moreau and Mouvet, 1991). Numerous fish deaths have been attributed to the pesticide contamination of waters (Thakkar and Muthal, 1980). The groundwater contamination due to pesticides has also been reported (Raju et al., 1982; Hallberg, 1989 and Alam, 1996).

The contamination of water of ponds, rivers and ground water sources with various pesticides and herbicides is posing a direct threat to human health. Figure 2 shows some pesticides contaminated areas of West Bengal in India (Thakkar and Pande, 1986) and it can be seen that the areal extent of contamination is usually large. Baron (1986) has reported the presence of various fungicides and insecticides in the groundwater in Monitoba. Ramachandran et al. (1991) have studied the contamination of groundwater due to the pesticides like Benzene Hexa Chloride (BHC) and Dichloro Diphenyl Trichloro ethane (DDT). They report the groundwater contamination with $\mathrm{BHC}$ in the range of 0.16 to $1.08 \mathrm{ppb}$. Between October 1992 and February 1993, 359 private wells in Northampton County were sampled and pesticides were detected in $14 \%$ of the shallow wells and $7 \%$ of the deep wells. Pesticides perco- lation in soils was found to be a function of well depth (Bruggeman et al., 1995).

Ricardo et al. (1998) reported drifting loss during application of iso-octyl ester of 2,4-D in air. In a study carried out in 1978, it was found that when a 1:1 mixture of 2,4-D and 2,4,5-T (2,4,5 trichloro-phenoxy acetic acid) was applied to a field in Florida at 4,480 $\mathrm{kg} \mathrm{ha}^{-1}, 54 \%$ of the applied herbicides remained in the soil profile even after 414 days with $37 \%$ being present in the top $15 \mathrm{~cm}$ soil layer; when the same was applied to a field in Washington, over $30 \mathrm{ppm}$ was found in leachates (Majka et al., 1982). Toxic hazards caused by many herbicides like atrazine, simazine, 2,4-D, 2,4,5-T, etc. on various aquatic organisms was studied by Grahan et al. (1979). Scott et al. (1981) reported that 2,4-DCP (2,4-dichloro phenol) was present in artificial ponds; they monitored the occurrence of 2,4-D and atrazine in natural waters. 2,4-D residue in water was $1 \mathrm{mg} \mathrm{l}^{-1}$ after 85 days of application in artificial ponds in cold condition. Residue was found even after 178 days. The persistence and degradation of 2,4-D in water was found to depend on temperature and oxygen content of water (Nesbitt and Watson, 1980; Birmingham and Colman, 1985). 


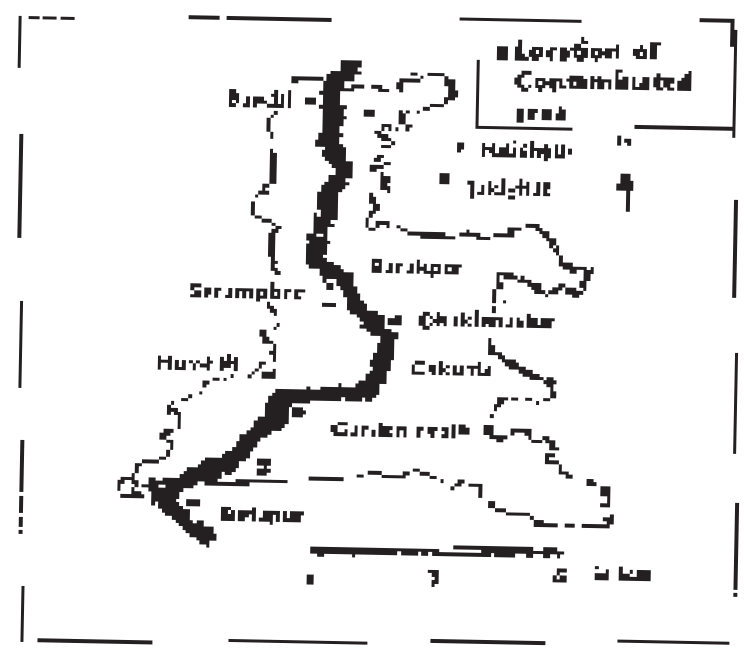

Figure 2. Pesticide contamination of canal waters in West Bengal, India

Blanchard and Donald (1997) reported that siteto-site variability in hydrology was more significant than the rate of application of herbicides. They examined the impact of hydrology for claypan soils, a naturally occurring argillic soil horizon that limits percolation to groundwater in Creek Watershed in north-central Missouri. Atrazine and alachlor were detected in $7.2 \%$ and $0.4 \%$ of samples respectively (Blanchard and Donald, 1997). Pesticide losses from cultivated fields may be a significant source of pollution for surface and groundwater. Richards et al. (1996) have reported the presence of atrazine in both surface and groundwater in an agricultural watershed located in southern Quebec though the atrazine accounted for only 5\% application in 1992 and $16 \%$ in 1993. Atrazine and simazine are the most widely used herbicides at present in U.S.A. and their residues were found in many surface and groundwater in U.S.A. (Gianessi and Puffer, 1991; Biradar and Rayburn, 1995; Nyholm et al., 1992; Tomlin, 1994 and Hill et al., 1986). Laroche and Gallichand (1995) reported the contamination of many ground and surface water supplies with primary metabolites of s-triazine compounds. These metabolites generally retain similar toxicological properties as parent compounds. They also found that as the percentage of the watershed area treated with atrazine increased, the higher concentrations were observed in the surface water. In India and Bangladesh also, the use of 2,4-D and atrazine herbicides has been found to increase every year, so, their presence in water environment is also on increase and is a matter of concern (Rita, 1998). The World Health Organization (WHO) drinking water quality standard is $20 \mu \mathrm{g} \mathrm{l}^{-1}$ for $2,4-\mathrm{D}$ and $3 \mu \mathrm{g} \mathrm{l}^{-1}$ for atrazine.

Activated carbon due to its high surface area and porosity is very efficient in removing varieties of pesticides from water and wastewater. The use of the activated carbon in removing many pesticides from aqueous phase has been demonstrated in the literature (Francis and Lee, 1972; Steiner and Edward, 1979; Pirbazari and Weber, 1984; Garcia-Rodriguez et al., 1987a; Jindal and Singh, 1988; Adams and Watson, 1996; Sudhakar, 1999). One of the first reports concerning the removal of herbicides from water by sorption technique was given by Aly and Faust, (1965). Adsorption by activated carbon was found to be the most promising method of removal of 2,4-D and atrazine also but this process is not cost-effective particularly in developing countries (Aly and Faust, 1965; Adams and Watson, 1996). In the present research work, a number of low cost adsorbents were investigated as an alternative to activated carbon to abate 2,4-D and atrazine herbicides from drinking water.

\section{EXPERIMENTAL METHODS \\ Preparation of Adsorbents}

Five low cost adsorbents, viz. wood charcoal, rubber granules, bottom ash, macro fungi sajor caju and florida were tested. Wood charcoal was collected from local market at Rs. $15 \mathrm{~kg}^{-1}$ (\$0.4 per $\mathrm{kg}$ ). Rubber granules, derived from recycled waste tire rubber, were provided by Birla Tyre Ltd., Orissa and Rubber Technology Center, IIT, Kharagpur. Bottom ash was collected from Kolaghat Thermal Power Plant, West Bengal. Local varieties of macro fungi sajor caju and florida were collected from Rural Development Center, IIT, Kharagpur and dried in sunlight for 2 days.

All adsorbent materials were washed thoroughly with distilled water to avoid the presence of foreign impurities. Then the washed and dried materials were pulverized and sieved to get adsorbent size $0.15-0.30 \mathrm{~mm}$. The sieved materials were washed thoroughly with distilled water to remove the fine particles. The washed materials were dried at $110^{\circ} \mathrm{C}$ for $10 \mathrm{hrs}$ and then cooled in a desiccator to the room temperature. The materials were once again sieved to the required size 
and were stored in separate airtight bottles. Out of five adsorbents, wood charcoal was treated with $0.1 \mathrm{~N} \mathrm{HNO}_{3}$ for increasing its sorption capacity. The treated wood charcoal was used as the adsorbent material in all the experiments.

\section{Reagents}

All the reagents used were of analytical grade. All glassware used was of Borosil. Distilled water was used for making synthetic samples. Before each experiment, all glassware were cleaned with dilute nitric acid and repeatedly with distilled water followed by drying at $110^{\circ} \mathrm{C}$ for $5 \mathrm{hrs}$. Technical grade 2,4-D of $95 \%$ purity was obtained from Vijayalakshmi Insecticides, India. Diethyl ether and toluene of $99.9 \%$ purity were used for the determination of 2,4-D by Gas Chromatography (GC).

Technical grade atrazine of $98 \%$ purity was obtained from Rallis India Ltd. For atrazine, ethyl acetate of 99.9\% purity was used for Gas Chromatography and dichloromethane of $98 \%$ purity was used for UVVisible spectrophotometer method.

\section{Analytical methods}

Standard methods (APHA-AWWA-WPCF, 1989) were adapted for the analysis of various water quality parameters. Gas Chromatograph (GC14A, Shimadzu, Japan) was used for the measurement of both 2,4-D and atrazine. Electron Capture Detector $\left({ }^{63} \mathrm{Ni}\right)$ with $5 \%$ OV-17 stainless steel porapak packed column was used. The column was of $3 \mathrm{~m}$ length and $3.18 \mathrm{~mm}\left(1 / 8^{\prime \prime}\right)$ diameter. For 2,4-D, temperatures for column, injector, and detector were maintained at $195^{\circ} \mathrm{C}, 250^{\circ} \mathrm{C}$, and $300^{\circ} \mathrm{C}$, respectively while the same were kept as $215^{\circ} \mathrm{C}, 220^{\circ} \mathrm{C}$ and $265^{\circ} \mathrm{C}$, respectively for atrazine. Nitrogen gas having $99.9 \%$ purity was used as carrier gas. Its flow rate was maintained as $50-60 \mathrm{ml} \mathrm{min}^{-1}$ for 2,4-D and $80-90 \mathrm{ml} \mathrm{min}^{-1}$ for atrazine. Before the actual measurements, the GC was conditioned for 48 hours to avoid column bleeding and soiling of sample and to maintain ideal conditions for every GC run.

Atrazine measurements were also cross-checked using UV-Visible spectrophotometer (UV 3100, Shimadzu, Japan) at $229 \mathrm{~nm}$ after the extraction of sample using dichloro-methane.

\section{Sample Preparation}

Stock solution of 2,4-D was prepared in distilled water while the stock solution of atrazine was made by dissolving it in acetone. All experiments were performed with a stock solution of $200 \mathrm{mg} \mathrm{l}^{-1}$, which was prepared afresh after every 10 days. The samples of required concentrations were prepared by diluting the stock solution with distilled water.

\section{Extraction of 2,4-D and Atrazine}

2,4-D was extracted from the representative sample $(100 \mathrm{ml})$ of aqueous solution containing 2,4-D by liquid-liquid partition in a $125 \mathrm{ml}$ separating funnel using diethyl ether. The extraction was done three times with $10 \mathrm{ml}, 10 \mathrm{ml}$, and $5 \mathrm{ml}$ of diethyl ether, respectively. During the extraction process, the sample-diethyl ether mixture was shaken for 5 minutes and then allowed to settle for 5 minutes. The separated layer of diethyl ether was passed through a $10 \mathrm{~mm}$ bed of sodium sulphate to absorb any trace moisture present in the extracted sample. Then diethyl ether extract was collected in a volumetric flask and evaporated to dryness and esterified by BF3-methanol and made to $25 \mathrm{ml}$ with toluene (APHA-AWWAWPCF, 1987). The extraction efficiency of diethyl ether was found out by measuring 2,4-D in three samples of known concentration by GC. This is supported by work reported by Grover and his coworkers (1985) in the literature. The extraction efficiency was found to be $80-87 \%$.

The extraction of atrazine from aqueous solution was also done in same manner as outlined above but ethyl acetate was used as the solvent. The extraction efficiency was found $90 \%-95 \%$.

\section{Kinetic Studies}

Polyethylene bottles (Tarson Co. Ltd., India) of 125 $\mathrm{ml}$ capacity were used in the kinetic experiments. Synthetic water samples $(100 \mathrm{ml})$ of $4 \mathrm{mg} \mathrm{l}^{-1}$ concentration of 2,4-D and atrazine were taken in separate set of bottles and the adsorbents were added to these at optimal dose. The sample bottles were shaken on a mechanical shaker at 150 $\mathrm{rpm}$. The experiments were carried out for a duration of $300 \mathrm{~min}$ at $27^{\circ} \mathrm{C}$ and the samples were collected every $10 \mathrm{~min}$ up to the first $80 \mathrm{~min}$, then every $20 \mathrm{~min}$. The adsorbent from the sample bottle was separated by gravity and the supernatant was measured for residual 2,4-D or atrazine, as the case may be. In case of sajor caju and florida, the samples were further clarified by centrifugation at $1200 \mathrm{rpm}$ for $15 \mathrm{~min}$ and the clarified supernatant was used for analysis of herbicides. 


\section{Equilibrium Studies}

Batch experiments were conducted for the development of adsorption isotherms for different materials under the same experimental condition (pH 5.8-6.0, adsorbent size $0.15-0.30 \mathrm{~mm}$ and temperature $27^{\circ} \mathrm{C}$ ). Polyethylene bottles of $125 \mathrm{ml}$ capacities were used in all the experiments. Herbicides spiked synthetic water samples (100 $\mathrm{ml}$ ) of $0.5,1,2.5,4.0$ and $7.5 \mathrm{mg} \mathrm{l}^{-1}$ concentration, respectively were taken in different bottles and adsorbate was added to it at a specified dose. The sample bottles were shaken on a mechanical shaker at $150 \mathrm{rpm}$. After required equilibrium time, the samples were withdrawn from the shaker and the adsorbent from the sample bottle was separated by gravity. In case of sajor caju and florida the samples were further clarified as specified earlier.

\section{RESULTS AND DISCUSSION Kinetic Studies}

Kinetic profiles of removal were generated for all the materials to assess the equilibrium time. Figure
3 shows the typical kinetic profile for rubber granules. For different adsorbents, after different times the profiles were found to be parallel to time axis indicating negligible further removal of the herbicides. Major parts of the adsorption occurred within the first 30-40 $\mathrm{min}$, although time varied with adsorbents. Thus on the basis of kinetic studies, different contact times for different adsorbents were adopted for adsorption experiments. For rubber granules (Fig. 3), equilibrium time was found to be 120 and $100 \mathrm{~min}$ for 2,4-D and atrazine, respectively. Table 1 shows the results of kinetic studies and corresponding efficiencies. It may be noted that the dose shown in the Table 1 has been selected on the basis of the optimal dose test. In that test, it was seen that after the optimum dose of an adsorbent, the increment of removal was not more than 2-4\%. Wood charcoal exhibited a removal of $92.7 \%$ of 2,4$\mathrm{D}$ and $95.5 \%$ of atrazine, which was less than removal efficiency of activated charcoal reported as $99.0 \%$ for 2,4-D (Aly and Faust, 1965) and 98\% for atrazine (Adams and Watson, 1996). Though wood
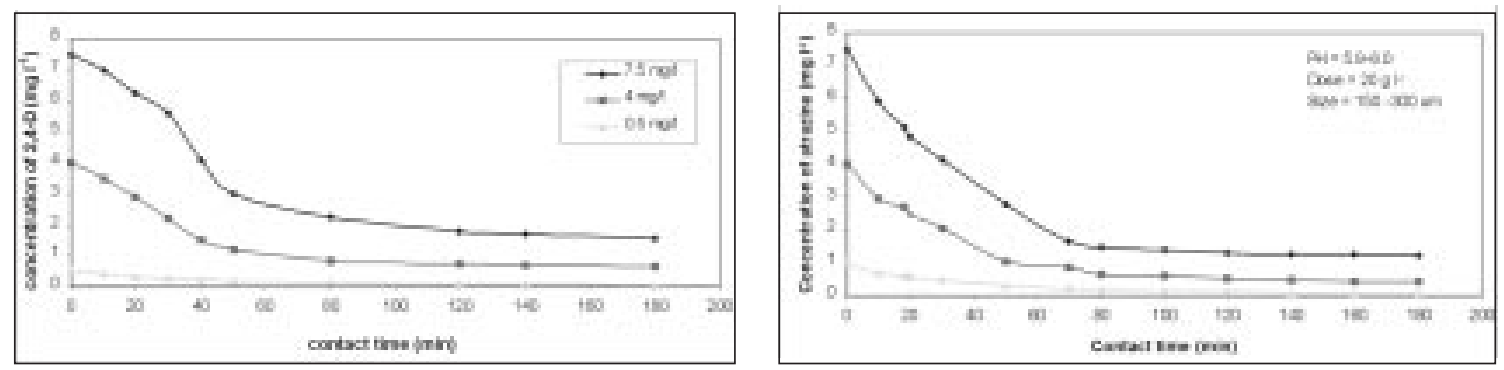

Figure 3. Kinetic profiles for (a) 2,4-D (b) atrazine on rubber granules for different initial concentration

Table 1. Results of kinetic studies with $4 \mathrm{mg} \mathrm{l}^{-1}$ initial concentration 2,4-D and atrazine

\begin{tabular}{|l|l|c|c|c|}
\hline Type of Herbicide & Type of Adsorbent & Dose $\left(\mathrm{g} \mathrm{l}^{-1}\right)$ & $\begin{array}{c}\text { Equilibrium } \\
\text { Time (min) }\end{array}$ & $\begin{array}{c}\text { Removal } \\
\text { Efficiency (\%) }\end{array}$ \\
\hline 2,4-D & Wood charcoal & 10 & 60 & 92.7 \\
\cline { 2 - 5 } & Rubber granules & 18 & 120 & 78.4 \\
\cline { 2 - 5 } & Bottom ash & 20 & 210 & 72.3 \\
\cline { 2 - 5 } & Sajor caju & 20 & 240 & 60.3 \\
\cline { 2 - 5 } & Florida & 20 & 240 & 59.3 \\
\hline \multirow{5}{*}{ Atrazine } & Wood charcoal & 10 & 45 & 95.5 \\
\cline { 2 - 5 } & Rubber granules & 20 & 100 & 82.8 \\
\cline { 2 - 5 } & Bottom ash & 20 & 210 & 76.0 \\
\cline { 2 - 5 } & Sajor caju & 20 & 240 & 62.3 \\
\cline { 2 - 5 } & Florida & & & 61.8 \\
\hline
\end{tabular}


charcoal exhibited slightly less adsorptive capacity (cost Rs. $15 \mathrm{~kg}^{-1}=\$ 0.4 \mathrm{~kg}^{-1}$ ) as compared to activated charcoal (cost Rs. $110-300 \mathrm{~kg}^{-1}=\$ 2.6-7 \mathrm{~kg}^{-1}$ ), it is definitely cost effective. Rubber granules, bottom ash, sajor caju and florida exhibited relatively low efficiency.

\section{Equilibrium Studies}

Equilibrium studies were carried out for all the materials to assess the adsorption equilibrium model that they followed. Langmuir, BET, modified BET, Freundlich and L-G isotherm models were considered. For a given set of experimental data, the model that gave the best correlation coefficient by linear regression method was adopted for the calculation of $\mathrm{Q}_{\max }$ of the corresponding adsorbent material.

To estimate $\mathrm{Q}_{\max }$ the linearized forms of Langmuir, BET, LG and Freundlich isotherms (GarciaRodriguez et al., 1987a) as given below were used:

$\mathrm{q}_{\mathrm{e}}=\frac{\mathrm{Q}_{\max } \mathrm{bC}_{\mathrm{e}}}{1+\mathrm{bC}_{\mathrm{e}}}$

[Langmuir model]

$\mathrm{C}_{\mathrm{e}} /\left(\mathrm{q}_{\mathrm{e}}\right)\left[1 /\left(\mathrm{C}_{\mathrm{s}}-\mathrm{C}_{\mathrm{e}}\right)\right]=1 /\left(\mathrm{B} \times \mathrm{Q}_{\max }\right)+$ $+(\mathrm{B}-1) /\left(\mathrm{B} \times \mathrm{Q}_{\max }\right)\left(\mathrm{C}_{\mathrm{e}} / \mathrm{C}_{\mathrm{s}}\right) \quad[\mathrm{BET}$ model $]$

$\mathrm{C}_{\mathrm{e}} /\left(\mathrm{q}_{\mathrm{e}} \times \mathrm{C}_{\mathrm{s}}\right)\left[1+\mathrm{K}\left(\mathrm{C}_{\mathrm{e}} / \mathrm{C}_{\mathrm{s}}\right)\right]=$ $=1 /\left(\mathrm{B} \times \mathrm{Q}_{\max }\right)+1 / \mathrm{Q}_{\max }\left(\mathrm{C}_{\mathrm{e}} / \mathrm{C}_{\mathrm{s}}\right)$

[L-G model]

$\log \mathrm{q}_{\mathrm{e}}=1 / \mathrm{n} \log \mathrm{C}_{\mathrm{e}}+\log \mathrm{K}_{\mathrm{f}}$ [Freundlich model] where $\mathrm{C}_{\mathrm{e}}$ is solute concentration at equilibrium in aqueous phase in $\mathrm{mg} \mathrm{l}^{-1}, \mathrm{C}_{\mathrm{s}}$ is saturation concentration of solute in $\mathrm{mg} \mathrm{l}^{-1}, \mathrm{q}_{\mathrm{e}}$ is solute adsorbed per unit weight of adsorbent in $\mathrm{mg} \mathrm{g}^{-1}, \mathrm{Q}_{\max }$ is maximum solute adsorbed per unit weight of adsorbent in $\mathrm{mg} \mathrm{g}^{-1}$ and $\mathrm{b}, \mathrm{n}, \mathrm{K}_{\mathrm{f}}$ and $\mathrm{B}$ are constants, $\mathrm{K}$ is a parameter related to the entropy of the adsorbate in the adsorbed phase. The $\mathrm{K}$ value is adjusted in such a way that the correlation coefficient of L-G model comes near to that of Langmuir or BET model (Garcia-Rodriguez et al., 1987b).

For a given adsorbent, the model that gave better correlation than others was finally selected as shown in Table 2.

It is evident from Table 2 that Freundlich model fitted well with experimental data for most of the cases. $\mathrm{K}_{\mathrm{f}}$ value gives sorption capacity of adsorbent for the equilibrium concentrations and $n$ value gives an idea about intensity of capacity. Since all the experiments were conducted under same experimental condition ( $\mathrm{pH}$ 5.8-6.0, adsorbent size $0.15-0.30 \mathrm{~mm}$ and temperature $27^{\circ} \mathrm{C}$ ), the sorption capacity is taken as a measure of maximum adsorption capacity for the comparison purposes. The respective linearised isotherms for various adsorbents for each herbicide are presented in Figs. 4, 5 and 6, which were used for determination of $\mathrm{Q}_{\max }$. The values of $\mathrm{Q}_{\max }$ for the various adsorbents are tabulated in Table 3.

For the selection of suitable adsorbent for 2,4-D and atrazine uptake, the maximum adsorption capacity $\left(\mathrm{Q}_{\max }\right)$ was chosen as the main parameter.

Table 2. Correlation coefficients for different adsorbents with different adsorption equilibrium models

\begin{tabular}{|l|l|c|c|c|c|c|}
\hline $\begin{array}{l}\text { Type of } \\
\text { herbicide }\end{array}$ & Adsorbent & $\begin{array}{c}\text { Langmuir } \\
\text { model }\end{array}$ & $\begin{array}{c}\text { BET } \\
\text { model }\end{array}$ & $\begin{array}{c}\text { Freundlich } \\
\text { model }\end{array}$ & L-G model & $\begin{array}{c}\text { Model } \\
\text { selected }\end{array}$ \\
\hline 2,4-D & Wood charcoal & 0.830 & 0.914 & 0.978 & $0.913(\mathrm{k}=0.1)$ & Freundlich \\
\cline { 2 - 7 } & Rubber granules & 0.90 & 0.962 & 0.961 & $0.954(\mathrm{k}=0.1)$ & BET \\
\cline { 2 - 7 } & Bottom ash & 0.834 & 0.887 & 0.941 & $0.887(\mathrm{k}=1)$ & Freundlich \\
\cline { 2 - 7 } & Sajor caju & 0.810 & 0.814 & 0.953 & $0.814(\mathrm{k}=1)$ & Freundlich \\
\cline { 2 - 8 } & Florida & 0.88 & 0.891 & 0.957 & $0.891(\mathrm{k}=1)$ & Freundlich \\
\hline \multirow{7}{*}{ Atrazine } & Wood charcoal & 0.919 & 0.926 & 0.956 & $0.92(\mathrm{k}=0.1)$ & Freundlich \\
\cline { 2 - 7 } & Rubber granules & 0.95 & 0.985 & 0.978 & $0.983(\mathrm{k}=0.1)$ & BET \\
\cline { 2 - 7 } & Bottom ash & 0.87 & 0.887 & 0.924 & $0.886(\mathrm{k}=1)$ & Freundlich \\
\cline { 2 - 7 } & Sajor caju & 0.756 & 0.79 & 0.928 & $0.786(\mathrm{k}=1)$ & Freundlich \\
\cline { 2 - 7 } & Florida & 0.689 & 0.736 & 0.947 & $0.733(\mathrm{k}=1)$ & Freundlich \\
\hline
\end{tabular}



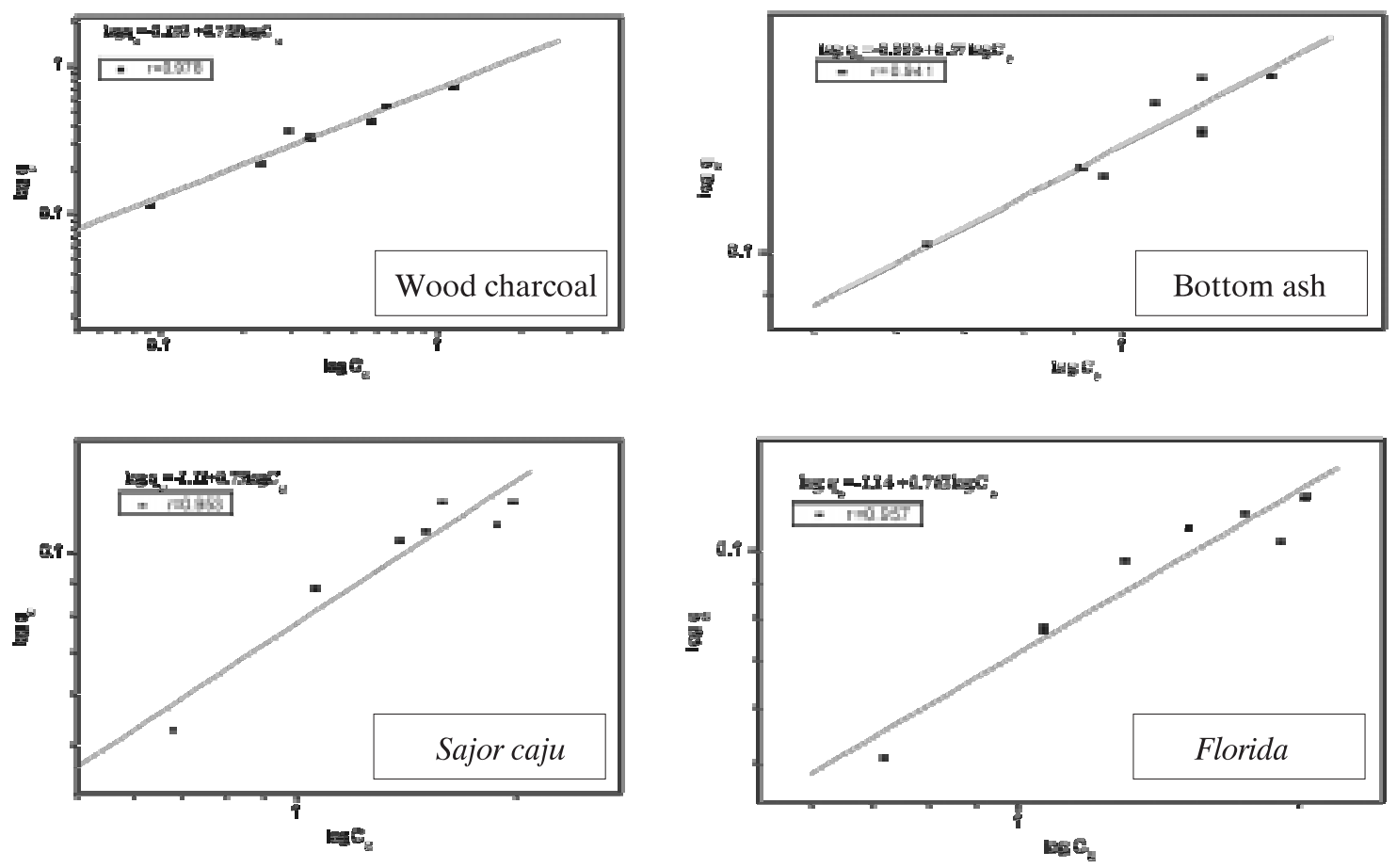

Figure 4. Freundlich isotherms for sorption of 2,4-D onto (a) wood charcoal, (b) bottom ash, (c) sajor caju, (d) florida.
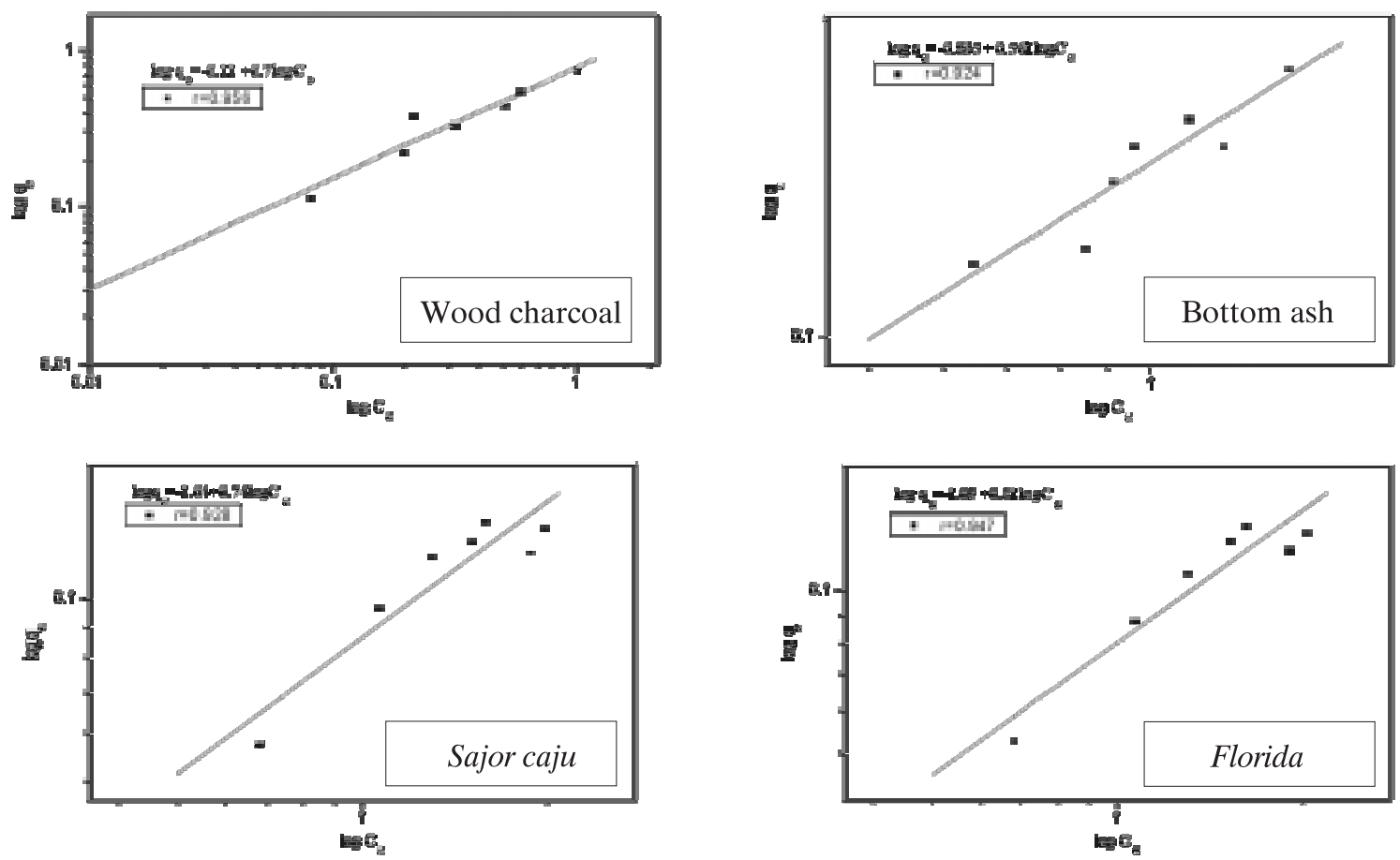

Figure 5. Freundlich isotherms sorption of atrazine onto (a) wood charcoal, (b) bottom ash (c) sajor caju and (d) florida. 

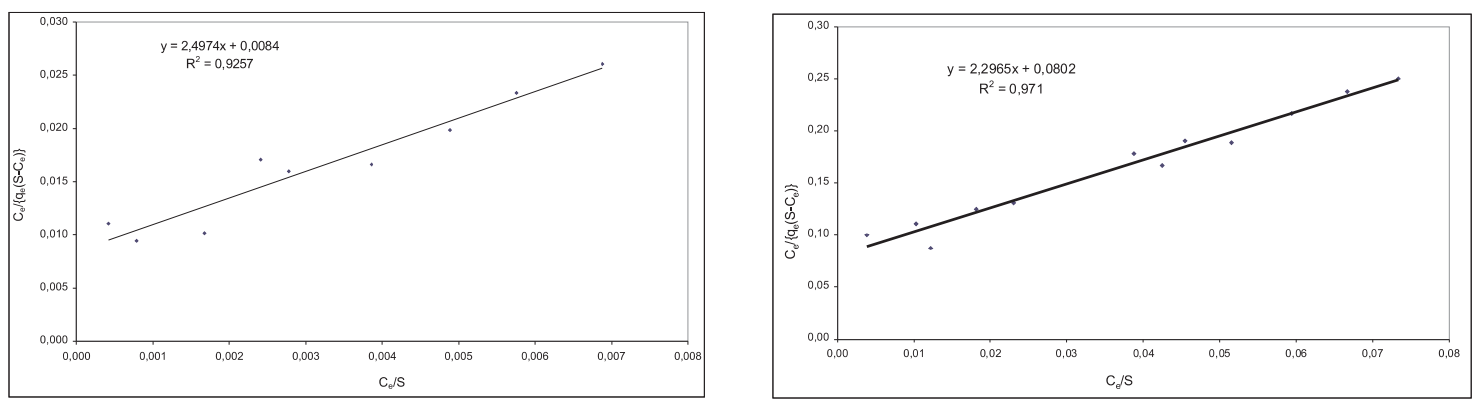

Figure 6. BET isotherms for sorption of (a) 2,4-D onto rubber granules, (b) atrazine onto rubber granules system

Wood charcoal showed the best $\mathrm{Q}_{\max }$ of $0.70 \mathrm{mg} \mathrm{g}^{-1}$ for 2,4-D with a correlation coefficient 0.978 for the Freundlich model and $0.80 \mathrm{mg} \mathrm{g}^{-1}$ for atrazine with a correlation coefficient 0.956 for the Freundlich model, respectively. Rubber granules followed wood charcoal with maximum capacity as $0.40 \mathrm{mg} \mathrm{g}^{-1}$ for 2,4-D with the BET model with a correlation coefficient 0.962 and $0.47 \mathrm{mg} \mathrm{g}^{-1}$ for atrazine with the same model with a correlation coefficient 0.985 , respectively. Wood charcoal showed high removal efficiency due to its higher surface area and honeycomb structure (Sudhakar, 1999). The uptake of herbicides by rubber granules could be for its polymer, carbon black. Sajor caju and florida not only showed poor performance in adsorption of herbicides but they also created color problem in the effluent.

Wood charcoal after being exhausted may create disposal problem and when burnt in the conventional boilers at high temperature may lead to addition- al air pollution problems. As rubber granules can be used for other additional purposes such as binder mixture of asphalt, it has no disposal problem. When rubber granules are heated with asphalt, the effects of herbicides will be nullified. The heating of rubber granules with asphalt will not create additional pollution because the percentage of rubber is only $5-10 \%$ and heating is done up to $160^{\circ} \mathrm{C}$ or less (Collins and Mikols, 1985; King et al., 1986). Only beyond $180^{\circ} \mathrm{C}$, the thermal separation and smoking of rubber polymer may occur (Hensley, 1998). Also, the emissions caused by using tire rubber in asphalt are found to be no greater than the conventional asphalt. Moreover, the noise pollution and the cost of road construction will be reduced (RPA, 1998).

\section{CONCLUSIONS}

Among the materials tested as alternatives to activated charcoal, wood charcoal showed the maximum adsorptive capacity, followed by rubber

Table 3. $\mathrm{Q}_{\max }$ for different adsorbents

\begin{tabular}{|l|l|c|c|}
\hline Type of herbicide & Adsorbents & Model followed & $\mathrm{Q}_{\max }\left(\mathrm{mg} \mathrm{g}^{-1}\right)$ \\
\hline \multirow{4}{*}{ 2,4-D } & Wood charcoal & Freundlich & $0.70^{*}$ \\
\cline { 2 - 4 } & Rubber granules & BET model & 0.40 \\
\cline { 2 - 4 } & Bottom Ash & Freundlich & $0.13^{*}$ \\
\cline { 2 - 4 } & Sajor caju & Freundlich & $0.08^{*}$ \\
\cline { 2 - 4 } & Florida & Freundlich & $0.07^{*}$ \\
\hline \multirow{4}{*}{ Atrazine } & Wood charcoal & Freundlich & $0.80^{*}$ \\
\cline { 2 - 4 } & Rubber granules & BET model & 0.47 \\
\cline { 2 - 4 } & Bottom Ash & Freundlich & $0.146^{*}$ \\
\cline { 2 - 4 } & Sajor caju & Freundlich & $0.087^{*}$ \\
\cline { 2 - 4 } & Florida & Freundlich & $0.08^{*}$ \\
\hline
\end{tabular}

* Sorption capacity taken as approximate measure of $\mathrm{Q}_{\max }$ 
granules. Wood charcoal is an easily and abundantly available material. However, after being exhausted, it is likely to create disposal problems and its burning may lead to additional air pollution problems. Although rubber granules showed lower efficiency than wood charcoal, rubber granules may not have disposal problems and it can be reused as binder mixture of asphalt. Thus among wood charcoal (Rs. $15 \mathrm{~kg}^{-1}=\$ 0.4 \mathrm{~kg}^{-1}$ ) and rubber granules (Rs. $20 \mathrm{~kg}^{-1}=\$ 0.47 \mathrm{~kg}^{-1}$ ), any one can be selected as the adsorbent for removal of 2,4-D and atrazine from the water environment to the WHO drinking water quality standard of $20 \mu \mathrm{g} \mathrm{l}^{-1}$ for 2,4-D and $3 \mu \mathrm{g} \mathrm{l}^{-1}$ for atrazine.

\section{ACKNOWLEDGEMENTS}

The authors would like to thank M/s Vijayalaxmi Insecticides and Pesticides Limited, Ethakota (A.P.), India and M/s Rallis India, Mumbai, India for providing technical grade 2,4-D and atrazine for undertaking the research outlined in the present paper.

\section{REFERENCES}

Adams, D.C. and Watson, L.T. (1996), Treatbility of s-triazine herbicide metabolites using powder activated carbon, J. Environ. Eng., ASCE, 39, 327-330.

Alam, J.B. (1996), Risk Assessment and Management of Selected Pesticides Generally Used in Bangladesh, M. Tech. Thesis, Bangladesh University of Engineering and Technology.

Aly, O.M. and Faust, S.D. (1965), Removal of 2,4-dichlorophenoxy acetic acid derivatives from natural waters, $J$. $A W W A, 221-230$.

APHA-AWWA-WPCF (1989), Standard methods for the examination of water and wastewater, American Public Health Association, NY.

Baron, D.S. (1986), Pesticide contamination of water supplies, Proceedings of Toxic Substances in Agricultural Water Supply and Drainage, Regional meeting of U.S. Committee on Irrigation and Drainage, California.

Biradar, D.P. and Rayburn, A.L. (1995), Chromosomal damage induced by herbicide contamination at concentrations observed in public water supplies, J. Environ. Qual., 24, 1222-1225.

Birmingham, B.C. and Colman, B. (1985), Persistence and fate of 2,4-D Butoxyethanol ester in artificial ponds, $J$. Env. Qual. 14, 100-104.

Blanchard, P.E. and Donald, W.W. (1997), Herbicides contamination of ground water beneath claypan soils in north central Missouri, J. Environ. Qual., 26, 1612-1621

Bruggeman, A.C, Mostaghimi, S., Holtzman, G.I., Shanholtz, V.O., Shukla, S. and Ross, B.B. (1995), Monitoring pesticides and nitrites in Virginia's groundwater-A pilot study, Trans. ASAE, 38, 797-807.

Collins, J.H. and Mikols, W.J. (1985), Block co-polymer modification of asphalt intended for surface dressing applications, Proceedings of the association of asphalt paving technologists, 54, 1-17.

Francis, R.B. and Lee, G.F. (1972), Adsorption of lindane and dieldrin pesticides on unconsolidated aquifer sands, Environ. Sci. Technol. 6, 538-543.

Garcia-Rodriguez, A., Jimenez, L. G., Dios, J., Gonzalez, L. and Guijosa, A. N. (1987a), Adsorption of 2,4,5-T by active carbons from aqueous solution, J. Chem. Tech. Biotechnol. 38, 1-13.

Garcia-Rodriguez, A., Gomez-Jimenez, L, Lopez-Gonzalez J. de D. and Navarrete-Guijosa, A. (1987a), Study of the kinetics of the adsorbent by activated carbons of 2,4,5-trichlorophenoxy acetic acid from aqueous solution, J. Chem Tech. Biotech. 37, 271-280.

Gianessi, L.P. and Puffer, C. (1991), Hebicide use in the United States, Resources for the future, Washington D.C. Graham, J.R., Yafee, J., Archer, T.E. and Bevanne, A. (1979), Chemical Analysis of pesticides, Thiden, 3.

Grover, R., Shewchuk, S.R., Cessna, A.J., Smith, A.E. and Hunter, J.H. (1985), Fate of 2,4 D iso-octyl ester after application to wheat field, J. Env. Qual. 14, 203-210.

Haldar, P., Raha, P., Bhattacharya, P., Choudhury, A. and Adityachoudhury, N. (1989), Studies on the residues of DDT and endosulfan occurring in Ganga water, Indian J. Environ Hlth., 31, 156-161.

Hallberg, G.R. (1989), Pesticide pollution of groundwater in the humid American States, Agril. Ecosystems Environ. 26, 299-367.

Hatfield, J.L., Wesley, C.K., Prueger, J.H. and Pfeiffer, R.L. (1996), Herbicide and nitrate distribution in Central Iowa rainfall, Nat.1 Soil Tilth Lab, Ames, IA, USA, J. Environ. Qual. 25, 259-264.

Hensley, W. (1998), Stabilizing Hot-Mix asphalt and compaction temperature at project level, Asphalt, 12, 19-23. Hill, N.P., McIntyre, A.E., Perry, R. and Lester, J.N. (1986), Behaviour of chloro-phenoxy herbicides during the activated sludge treatment of municipal wastewater, Wat. Res., 20, 45-52. 
Jindal, R. and Singh, J. (1988), Toxicity of pesticides to the productivity of a fresh water pond, Indian J. Environ. Hlth. 31, 257-261.

Joshi, H.C., Kappor, D., Panwar, R.S. and Gupta, R.A. (1975), Toxicity of some insecticides to Chironomic Larvae, Indian J. Environ. Hlth. 17, 238-341.

King, G.N., Muncy, H.W. and Prudhomme, J.B. (1986), Polymer modification: Binder's effect of mixing properties, Proceedings of the association of asphalt paving technologists, 55, 519-540.

Laroche, A.M. and Gallichand, J. (1995), Analysis of pesticide residues in surface and groundwater of a small watershed, Tran. of the ASCE, 38, 1731-1736.

Majka, J.T., Cheng, H.H. and Mcneal, B.L. (1982), Mobility of 2,4-D and 2,4,5-T n-Butyl esters in soils following massive application to field minilysmeters, J. Env. Qual. 11, 650-654.

McTernon, W.F. and Pereira, J.A. (1991), Biotransformation of lindane and 2,4-D in batch environment cultures, Wat. Res. 25, 1417-1423.

Moore, J.W. and Ramamoorthy, S. (1984), Organic Chemicals in Natural Waters, Applied Monitoring and Impact Assessment, Springer-Verlag Inc.

Moreau, C. and Mouvet, C. (1997), Sorption and Desorption of atrazine, deethylatrazine and hydroxyatrazine by soil and aquifer solids, J. Environ. Qual. 26, 416-424.

Nesbitt, H.J. and Watson, J.R. (1980), Degradation of the herbicide 2,4-D in river water, II, The role of suspended sediment, nutrients and water temperature, Wat. Res. 14, 1689-1694.

NMIDP (1995), Base Line Survey Water Quality Part 1, National Minor Irrigation Development Project, Ministry of Agriculture, Bangladesh.

Nyholm, N., Jacobsen, B.N., Bodil, M., Pedersen, O., Damborg, A. and Schultz, B. (1992), Removal of organic micro-pollutants at ppb levels in laboratory activated sludge reactors under various operating conditions: Biodegradation, Wat. Res. 26, 339-353.

Pirbazari, M. and Weber Jr., W.J. (1984), Removal of dieldrin from water by activated carbon, J. Environ. Engg. Divn. ASCE, 110, 656-669.

Raju, S.G., Visweswariah, K., Galindo, J.M.M., Khan, A. and Majumdar, S.K. (1982), Insecticide pollution in potable water resources in rural areas and related decontamination techniques, Pesticides, 16, 3-6.

Ramachandran, S., Narayanan, A. and Pundarikanthan, N.V. (1991), Nitrate and pesticides concentrations in groundwater of cultivated areas in north Madras, Indian J. Environ Hlth, 33, 421-424.

Rao, V.S. (1996), Contamination of village drinking water ponds with pesticide residue, Indian J. Environmental Protection, 16, 505-507.

Ricardo, D.D., Hernandez, J.E.G. and Loague, K. (1998), Leaching potentials of four pesticides for Bananas in the Canary Islands, J. Env. Qual. 27, 562-572.

Richards, R.P., Baker, D.B., Creamer, N.L., Kramer, J.W, Ewing, D., Merryfield, B J. and Walker, L.K. (1996), Well water quality, well vulnerability and agricultural contamination in the Midwestern United States, J. Environ. Qual. 25, 389-402.

Rita, K. (1998), Analytical studies on the determination of some pesticide residues and toxic substances in the environmental samples, Ph. D thesis, Ravishankar University, Raipur, India.

RPA, (1998), The FAQ report, Rubber Pavement Association, USA.

Scott, B.F., Paiter, D.S., Nagy, E., Dutta, E.J. and Tayler, W.D. (1981), Fate and effects of 2,4-D formulations as herbicides in aquatic eco-systems, Part I, L7R4A, National Water Research Institute, Canada, Center for Inland Waters, Burlington, Ontario, Canada.

Subbarao, M., Gajbhiye, V.T., Jain, H.K., Jain, M.C. and Agnihotri, N.P. (1986), Pesticide residues and other pollutants in Yamuna water at Delhi, Proc. Sympo. Pest. Resid. and Environ. Pollu., 113-121.

Sudhakar, Y. (1999), Abatement of Endosulfan from water environment by indigenous wood charcoal, PhD thesis, IIT, Kharagpur, India.

Srivastava, U.K. and Patel, N.T. (1990), Pesticides Industry in India, Oxford and IBH Publishing company Ltd., New Delhi.

Steiner IV, J. and Edward, J.S. (1979), Methoxychlor removal from potable water, J. AWWA, 71, $284-286$.

Tomlin, C. (Ed.) (1994), The Pesticide Manual, Crop protection publication, 10th edition, UK.

Thakkar, N. and Muthal, P.L. (1980), Granular activated carbon in pesticide removal, Indian J. Environ. Hlth. 22, 124-129.

Thankar, N. and Pande, S.P. (1986), Study of organochloro pesticides in some urban water resources, $I W W A$, XVIII, 313-316. 